\title{
Professional Development Activities that Shape Teachers' Perspectives on the Curriculum Project in Lesotho
}

\author{
Tafai Mapapali Gladys*, Tsakeni Maria
}

Faculty of Education, University of the Free State, South Africa

Received December 1, 2021; Revised January 11, 2022; Accepted February 16, 2022

\section{Cite This Paper in the following Citation Styles}

(a):[1] Tafai Mapapali Gladys, Tsakeni Maria, "Professional Development Activities that Shape Teachers' Perspectives on the Curriculum Project in Lesotho," Universal Journal of Educational Research, Vol. 10, No. 3, pp. 246 - 259, 2022. DOI: 10.13189/ujer.2022.100307.

(b): Tafai Mapapali Gladys, Tsakeni Maria (2022).Professional Development Activities that Shape Teachers' Perspectives on the Curriculum Project in Lesotho. Universal Journal of Educational Research, 10(3), 246 - 259. DOI: 10.13189/ujer.2022.100307.

Copyright $\bigcirc 2022$ by authors, all rights reserved. Authors agree that this article remains permanently open access under the terms of the Creative Commons Attribution License 4.0 International License

\begin{abstract}
This paper stems from the notion that the redesigning of effective continuing professional development (CPD) should be informed by teachers' perspectives. CPD is described as the lifelong education of professionals on specialized knowledge, skills, attitudes and ethical and moral values after the initial registration and admission to the profession. This qualitative study used sense-making theory (SMT) and the Desimone framework for effective professional development to explore how CPD activities had shaped the teachers' perspectives on the Lesotho integrated curriculum innovation. Data were collected through document analysis, semi-structured interviews and lesson observations, with four primary school teachers purposively selected from Leribe and Berea districts in Lesotho. Data were analysed using thematic and descriptive content analysis techniques. The findings of the study showed that the teachers' perspectives on the curriculum project that were shaped by $\mathrm{CPD}$, were their beliefs on the use of learner-centred approaches, their perceptions on the use of integrated assessment approaches, their attitudes towards the usefulness of the integrated curriculum and their beliefs on whether teacher development influenced learner outcomes. The study recommends that CPD should be designed to have a greater influence on teachers.
\end{abstract}

Keywords Continuous Professional Development (CPD), Effective Professional Development, Integrated
Curriculum Training, Teacher Perspectives

\section{Introduction}

Despite the fact that CPD programmes have been accepted generally as essential tools for the development of teachers, studies continuously identify the ineptitude of some of these programmes [1]. This is because there are several forms of CPD that differ extensively in their structure [2]. This leaves a question mark about how something that can manifest so differently is commonly assumed to be good. There are factors that hinder the effectiveness of CPD and that differ from country to country and from school to school. Some limitations of the CPD programme such as using a one-size-fits-all approach to teacher training and using facilitators as the only source of knowledge while ignoring teachers and beneficiaries [3].This study used a background of the implementation of the integrated curriculum (IC) in Lesotho to explore the nature of CPD activities using teachers' perspectives. This study explored how CPD activities for the implementation of the IC shaped the teachers' perspectives on the curriculum project that began in 2013 in Lesotho. The study gives voice to the teachers by eliciting insights of how CPD experiences shaped their understanding of the IC implementation. The study contributes to the literature on 
the perspectives that teachers have on curriculum projects after going through CPD programmes.

\section{Background}

Countries around the world carry out reforms in education systems and Lesotho is not an exception in this regard. One of the major reasons for educational reforms development worldwide is to respond to global patterns of educational change. The IC was adopted in order to promote the "practical application of concepts and skills in most subjects" in order to alleviate poverty, unemployment and disease and to promote self-reliance [4].The IC was enacted after the Curriculum and Assessment Policy (CAP) was introduced in 2012 in Lesotho. It was first implemented countrywide in 2013, commencing with the foundation phase [5]. It gradually moved to grades four, five, six and seven in 2014, 2015, 2016 and 2017 respectively.

It is acknowledged that the IC approach to teaching and learning promotes democratic values and learner-centred approaches, encourages life-long learning and promotes work-related competencies [6],[5], which lead to the ability to solve practical problems and the striving for self-reliance [7]. The adoption of IC in schools engages learners progressively in learning and assessment, as opposed to examination-oriented curricula, which are judgmental and teacher-centred [8], hence it provides an enabling environment for a more fruitful teaching and learning process to take place [9]. However, the successful implementation of the IC relies heavily on the teachers' readiness and understanding of this new curriculum as well as on the available resources. For example, Tankiso-Mphunane [10] reports that successful implementation depends on a thorough understanding of the IC and Nhlapho, Moreeng and Malebese [9] indicate that "without adequate understanding, teachers think an IC is some kind of a teaching method, and so, continue to teach in out-dated, traditional ways, rather than using the IC as a new way of producing knowledge". These implementation challenges are prevalent in Lesotho, and impinge negatively on integrated teaching. Therefore, CPD programmes are highly needed in order to assist teachers in Lesotho. The study explored the CPD activities for the implementation of the IC that shaped the teachers' perspectives on the curriculum project in Lesotho.

\subsection{Research Question}

How do the CPD activities for the implementation of the IC shape the teachers' perspectives on the curriculum project in Lesotho?

\section{Literature}

\subsection{Teachers' CPD in Context of National Reform}

CPD is defined differently in the literature. Remijan [11] views teachers' CPD as training focused on improving teachers' performance and learners' outcomes. In this study, CPD is defined as any series of teacher training activities and life-long learning that improves teachers' knowledge, skills beliefs and attitudes for the implementation of curricula such as the IC in Lesotho. There are several factors that influence the effectiveness of CPD and its effects on teachers and learners' outcomes. These factors include the following, inter alia: "the critical features of professional development, teacher knowledge and beliefs, classroom practice, and learners' outcomes" [12]. This is because developing teacher quality through CPD is said to be dynamic, therefore there is a need to train the teachers properly [13]. Based on the above analysis, Fullan [14] argues that in order for CPD to be effective, teachers have to collaborate and work together to share knowledge and skills. It is also maintained that collaborative CPD is one of the critical features of CPD that leads teachers to gain confidence and improve their teaching practice [15]. In contrast, although CPD is put in place to develop teachers, the importance tends to differ considerably by individual and school context [16]. Teachers reported that they still face low access to supporting materials that should help them to implement reforms effectively, even though training is provided [17]. All in all, teachers still face some challenges in the classrooms even though they participate in CPD [18].

\subsection{CPD in Lesotho}

CPD is an important tool that enables teachers to successfully implement reforms in schools [19]. Therefore, CPD courses for teachers have been offered in Lesotho by different institutions and most of them have been run by the Ministry of education and training (MoET)[20].The forms of CPD that were predominantly used in Lesotho are the cascade model of CPD and cluster workshops aimed at equipping teachers with the required skills and knowledge. Khechane [21] further reports that the CPD programmes were in the form of short training sessions, which were usually held during the school holidays and one or two teachers from each school participated. Surprisingly, these CPD programmes provided to teachers seemed to have the same effect as once-off workshops because of the long time that lapsed before follow-up sessions could be conducted. The above statement implies that teachers were provided with inadequate support to implement the reforms. Shelile and Hlalele [22] articulate that "the other challenge of CPD in Lesotho is an acute shortage of staff to offer CPD activities". 


\subsection{CPD and Teacher Change}

Teachers are regarded as the agents of change in schools [23].Their development and their perspectives should therefore be taken into consideration through their participation in various CPD activities. Atta [24] defines teacher perspectives as teachers' attitudes, values and beliefs based on personal experience that helps them to interpret their teaching practice. Teachers' perspectives are particular ways of viewing things based on experience and personality or a way of thinking about something [24]. Therefore, in this study, teachers' perspectives were demonstrated through their perceptions because these influence teachers' activities and decision making in the teaching and learning process. Kuzborska [25] indicates that there is a strong relationship between the teachers' beliefs and their classroom practices, although there is no distinction about how they influence one another. Park and Sung [26] point out that the success of reform implementation relies on the teachers' acceptance of the reforms and their own principles as they are the ones who put reform ideas into practice [26].Furthermore, teachers' attitudes and beliefs are other crucial factors that determine the success or failure of curriculum implementation. For instance, according to Donaghue [27], teachers' beliefs serve as a guide for their teaching practice. In this regard, teachers' "beliefs about and understanding of any reform are recognised as essential in influencing whether reforms happen as intended and promote long-lasting change" [28: 30].

CPD activities are important for classroom practice improvement and for improving learning outcomes. This is because CPD activities change teachers' beliefs of their teaching practice which in turn influences classroom practice [29]. However, based on the assumption that CPD programmes can change teachers' attitudes and beliefs, it is important to involve them in the planning sessions in order to make sure that there is alignment between the new strategies and the teachers' needs [30]. Pedder's [31] study reported changes in teacher attitudes and beliefs as a result of teachers having participated in CPD programmes. Although CPD is said to have the power to change teachers for the better, Guskey [29] argues that it is the teachers' experience in the process of reform implementation that changes their attitudes and beliefs, but not the professional development per se. Teachers consider CPD to be working when they observe good results, and that is, their experiences shape their attitudes and beliefs in ways that improve their understanding of the curriculum to be implemented.

\section{Theoretical Framework and Conceptual Framework}

This paper, informed by sense-making theory (SMT) proposed by Spillane, Reiser and Reimer [32] and Desimone's (2009) [2] five-featured framework of effective PD, aims to explore how CPD activities for the implementation of the IC shaped the teachers' perspectives on the curriculum project in Lesotho. Schechter et al. [33] define sense-making as a process whereby people construct meaning by relating new information to their prior knowledge in order to act on it. Spillane et al. [32] assert that "sense-making is not a simple decoding of the policy message but it is an active process of interpretation that draws on the individual's rich knowledge based of understanding, beliefs and attitudes". This shows that a connection exists between teachers' sense-making about reforms and their perspectives on the implementation of such reforms. The SMT is "rooted in three aspects, namely; a) individual cognition/effect, b) situation/context and c) policy signals" [32: 389]. Table 1 explains this aspect of STM.

Under individual cognition, it is clear that teachers' perspectives about the reform are shaped and influenced by their prior knowledge, attitudes/beliefs, contextual factors and policy signals [34]. This is because when teachers engage with reforms, they are expected to change their practice. As a result, one may find out that the expectations that come with reforms may likely fit or not fit with teachers' prior knowledge. Therefore, the effective adaptation to the reforms depends on whether the changes to be made fit well with the teachers' prior knowledge or not. It is therefore argued in the literature that teacher' attitudes and beliefs about classroom practice are drawn from their past experiences and this guides their interpretation of the reform [34]. The SMT provided a lens for an in-depth exploration of teachers' perspectives on how the CPD activities that teachers participated in shaped their attitudes and beliefs for classroom implementation of the IC. The use of SMT enabled the researchers to explore teachers' views and how they make sense of the CPD programmes for the IC implementation.

Table 1. Descriptions of three aspects of SMT

\begin{tabular}{|c|l|}
\hline Aspects of SMT & \multicolumn{1}{c|}{ Descriptions } \\
\hline $\begin{array}{c}\text { Individual cognition/ } \\
\text { effect }\end{array}$ & $\begin{array}{l}\text { This means that individuals are sense-makers because they develop interpretation about the programme based on } \\
\text { their prior knowledge, beliefs and experiences. }\end{array}$ \\
\hline Situation/ context & $\begin{array}{l}\text { This indicates that the implementation agents are also social sense- makers and that all sense-making is "embedded } \\
\text { in social context" [32: 404]. That is the attitudes and beliefs of peers and administrators, the quantity and quality of } \\
\text { support individuals receive during implementation influence programme quality (ibid). }\end{array}$ \\
\hline Policy signals & $\begin{array}{l}\text { This indicates that "sense-making consists of policy signals or the role that the developments of representations of } \\
\text { ideas about change have on perceptions of the programme and how those influence implementation" [32: 389]. }\end{array}$ \\
\hline
\end{tabular}


Desimone' five-featured framework consists of two components. The first one involves identification of a set of core critical features for effective CPD. These features are (a) "content focus, (b) active learning, (c) coherence, (d) duration and (e) collective participation" [2: 184]. The second component establishes an operational theory for how the PD is assumed to work to influence teachers, instruction and learners [2]. This paper employed the second component that concerns an operational theory of how the PD is assumed to work to influence teachers, learners and practice. The second component reflects that teachers' experiences from PD (with certain core critical features) result in changes of teachers' knowledge and beliefs, which in turn foster changes in their instructional practices and improve learners' outcomes [2]. Kang, Cha, and $\mathrm{Ha}$ [62] affirmed that the framework by Desimone (2009) includes: (1) what effective PD is, (2) how it is supposed to affect teachers, instruction and learners and (3) the contextual factors that could impact the PD. According to [2] and [1], this framework suggests a sequence of events from learning activities to changes in knowledge, beliefs, attitudes, practice and finally the learners' improvement. In these CPD programmes, teachers are involved in the planning sessions after the programme organisers have conducted surveys to ensure that the new practices are well aligned with what teachers think would work better for them [2]. Pedder [31] maintained that as a result of teachers' participation in CPD programmes, they must have learned something and they may also have to undergo a change in beliefs. However, other internal characteristics may influence how teachers respond to change [35]. The combination of these two frameworks helped the researcher to understand the views of the teachers regarding how the CPD programmes that they received for the implementation of the IC shaped their perspectives.

\section{Methodology}

\subsection{Research Design}

A qualitative interpretive paradigm was adopted in this study because it allowed the researcher to understand the individuals' perceptions and insights of the world [36] and to "make sense or to interpret the phenomena in terms of the meanings people bring to them" [37].

\subsection{Context}

This study employed a multi-case study design which provided the structure that could be used to "acquire an understanding of the important characteristics of CPD and the relationships between the identified characteristics and professional learning experiences" [38], as well as the outcomes [39]. This is a multiple case study consisting of case studies of four participants from different schools (two schools from Berea and the other two from Leribe District). This number of participants enabled the researchers to gather information that allowed for a deeper understanding of the teachers' views and experiences of CPD for IC in different school settings. The CPD for IC in Lesotho was provided to teachers using the cascade model by training a few teachers in an information dissemination workshop at a central point. The trained teachers used the information received to facilitate quarterly workshops for the rest of the teachers in their respective school clusters. The use of multiple cases enabled a cross-case analysis and a comparison of the teachers' views of the teaching practice in different settings [40]. The different school settings allowed the researchers to contrast and compare the findings from the government, the church and the privately owned primary schools in Lesotho.

\subsection{The Participants}

Purposive sampling, one of the non-probability sampling strategies, was used based on the aim of this paper [36]. "Purposive sampling is defined as an approach whereby participants are chosen because they hold and present relevant data that is needed for the study in order to obtain the richest data that may answer the research questions" [41]. Purposive sampling was found to be appropriate for this study because it enabled the researcher to select the participants who participated in CPD activities for the classroom implementation of the IC and who are currently engaged in the implementation of the new curriculum. The four participants selected were Grade 2 teachers from four different schools. One participant was selected from a school that is owned by the government (Mrs Green); one was selected from a church primary school (Mrs Yellow), one from a private school (Mr Red) and the fourth one from a community school (Mrs Orange).

\subsection{Data Collection Instruments}

Semi-structured interviews and non-participant classroom observations were used to collect the data used to address the research question of this study. A semi-structured interview of each participant was conducted before each lesson observation. The classroom observations lasted at least 30-35 minutes for two different sessions per participant [36]. A total of 16 lesson observations were conducted over an eight-week period. This translated into 4 lesson observations per participant. Semi-structured interviews were used to provide information about the teachers' views on how CPD activities shaped their perspectives as they implemented the IC. These interviews permitted the interviewer to probe for clarification of their responses in cases where they did not give a clear response [42]. This technique was appropriate for this study because it gave the researcher a chance to get an in-depth insight from the teachers by allowing an opportunity to make follow-ups on ideas and 
probe for teachers' responses [42].

\subsection{Data Collection Procedures}

Data from the interviews were collected through the use of an interview protocol (Appendix 1) and an audio recorder. Thereafter, the audio-recording was transcribed into a written text which was coded, categorized and analysed for content, with the aim of identifying the themes into which the data fitted. Relationships and comparisons between the themes were established through cross-case analysis techniques.

The non-participant classroom observations were guided by a classroom observation protocol. The researcher only observed, recorded and took notes, but did not take part in the observed activity. Classroom observations were used in order to maintain the trustworthiness of this study because according to Johnson \& Christensen [43] "recording actual behaviour is better than obtaining reports of preferences or intended behaviour because people do not always do what they say they do". The data collected through the classroom observations were compared to what the participants said they did in the classroom when they were interviewed.

\subsection{Trustworthiness}

For this qualitative case study, credibility and trustworthiness were maximised through member checks and prolonged engagement in the field (eight weeks). A number of ethical concerns were attended to. The participants were informed of the aim of the research and were ensured of the confidentiality of the data that they provided and that their names were replaced with pseudonyms or omitted altogether while transcribing the audio recordings. All forms of collected data (printed transcripts or audio recordings) were kept safe in a lockable filing cabinet and any electronic data files were secured in a password-protected computer [40]. The researchers received ethical clearance from the University of the Free State and the Ministry of Education and training (MoET) in Lesotho to conduct this research in the selected schools.

\subsection{Data Analysis}

The data collected using semi-structured interviews and lesson observations were analysed using thematic content analysis [44]. The themes were built across a case analysis of the data collected from the four participants. Further inductive analysis processes were also used to identify the relationships between the CPD and participants' perspectives regarding the implementation of the IC [39]. The interview questions were formulated from the one main theme, which is the shaping of teachers' perspectives on the integrated curriculum implementation. The collected data were coded as shown in Table 2.

Similarly, the data collected using the classroom observations and the field notes were merged into interview transcripts and were then coded in order to generate the categories which were later assigned to the themes that were analysed using thematic content analysis [44]. The data was analysed based on the themes generated from the interviews and further analysed using an inductive analysis [39], in order to identify the impact of CPD on teachers' perspectives on the implementation of the IC. Table 3 shows how data were coded.

Table 2. Excerpt from interview codebook

\begin{tabular}{|c|c|c|c|}
\hline Code & Description code & Examples from interview extracts & Categories \\
\hline $\begin{array}{l}\text { How do the CPD activities for the } \\
\text { implementation of the IC shape the } \\
\text { teachers' perspectives on the } \\
\text { curriculum project in Lesotho? }\end{array}$ & $\begin{array}{l}\text { Description of shaping of } \\
\text { teachers' perspectives by } \\
\text { CPD. }\end{array}$ & $\begin{array}{l}\text { We are trained to use learner centred } \\
\text { strategies and how to use continuous } \\
\text { assessment and we are applying them } \\
\text { in classroom. }\end{array}$ & $\begin{array}{ll} & \text { knowledge } \\
\text { - } & \text { Beliefs } \\
\text { - } & \text { Attitudes } \\
\text { - } & \text { - Leaner outcomes } \\
\end{array}$ \\
\hline $\begin{array}{l}\text { Judgment on teachers' changed } \\
\text { perspective }\end{array}$ & $\begin{array}{l}\text { Expression of pros and } \\
\text { cons of CPD in changing } \\
\text { teachers' perspective. }\end{array}$ & $\begin{array}{l}\text { We believe that CPD activities had } \\
\text { changed the manner at which we } \\
\text { implement IC. }\end{array}$ & Perception. \\
\hline
\end{tabular}

Table 3. Excerpt from the lesson plan of teaching codebook

\begin{tabular}{|c|c|c|c|}
\hline Code & Description code & $\begin{array}{c}\text { Examples from lesson } \\
\text { extracts }\end{array}$ & category \\
\hline $\begin{array}{c}\text { description of shaping of } \\
\text { teacher' perspective by CPD. }\end{array}$ & $\begin{array}{c}\text { Used teacher-centred instead of } \\
\text { leaner-centred but follow } \\
\text { assessment criteria according to } \\
\text { their lesson plans and learners' } \\
\text { participation varied. }\end{array}$ & $\begin{array}{c}\text { Teaching strategies } \\
\text { Assessment methods } \\
\text { Learners participation and } \\
\text { outcomes }\end{array}$ \\
\hline
\end{tabular}




\section{The Findings}

The major predetermined theme was articulated as the shaping of teachers' perspectives on the IC implementation through the CPD programmes. The four perspectives that were demonstrated by the teachers were:

a) Perceptions on teacher knowledge to implement IC,

b) Teacher beliefs on IC assessment implementation,

c) Teacher attitudes on IC implementation and

d) Teacher perceptions on IC learner outcomes

\subsection{Theme 1: Shaping of teachers' perspectives on the integrated curriculum implementation by the CPD programmes}

\subsubsection{Sub-theme 1: Perceptions on teacher knowledge to implement IC}

The CPD programmes equip teachers with the relevant knowledge and skills regarding the implementation of reforms in schools. Mrs Green from GP School indicated that the kind of CPD programmes that she participated in was helpful because she acquired some new knowledge and skills on how to teach the IC and this changed the way she perceived the new curriculum:

I have acquired new IC knowledge and skills.

Mrs Green's view indicated that the CPD helped her to teach the IC as prescribed in the CAP, but surprisingly all of her lessons observed revealed a different story. She did not use learner-centred methods prescribed by CAP. She mainly used a question and answer method of teaching to reinforce the learners' participation in the lessons rather than to initiate any interaction or more opportunities for the learners to take full responsibility for their own learning. There was a contradiction between Mrs Green's perceptions and her teaching practice. It may be concluded that although Mrs Green indicated that CPD positively changed her perceptions, her teaching practice still matched the teaching of the previous curriculum that was dominated by teacher-centred approaches.

Mrs Yellow from CHP School had the same view as Mrs Green, she indicates that:

CPD programmes helped me to improve my teaching of the IC because they equipped me with teaching strategies and how to approach the learners.

Mrs Yellow was of the opinion that she was competent in teaching the IC according to the CAP but she did not use the appropriate teaching strategies proposed by the CAP. She tried to group the learners but not every learner participated in. In the end the teacher-centred discourse dominated the lesson presentation. The teacher moved around to check how the learners were doing but Mrs Yellow provided all the information for the learners instead of helping them to get to the correct answers. The extract below supports this statement.

Mrs Yellow: Today we are going to learn about different Basotho music genres. In ten minutes make groups of five members and discuss about different Basotho music genres.

Learners: Yes teacher.

Mrs Yellow. Ok class; now write five different Basotho music genres that you know and the group of people who dance for them in terms of boys and girls.

Mrs Yellow moved around to mark the groups. Not all the learners participated in these groups. The learners were passive. Mrs Yellow provided the answers for each group instead of letting each group present their findings so that members of the group could learn from each other,

Mrs Yellow: group one Basotho music genres are Mohobelo and ndlamo done by boys, Mokhibo and mokopu done by girls.

Group one learners: yes teacher.

Mrs Yellow: (now shouting) groups I said Basotho music genres are Mohobelo done by boys and Mokhibo done by girls...

The two extracts above imply that Mrs Green and Mrs Yellow used teacher-centred approaches as their mode of instruction instead of learner-centred approaches. Their teaching practice was still dominated by teacher-centred approaches that were not in line with the IC teaching strategies. These extracts contradicted their perceptions as they claimed to have gained an understanding of how to teach IC from the CPD activities.

Mrs Orange from CP school said that the workshops equipped her with limited skills regarding the implementation of the IC:

The workshops helped me to have few skills of integrating the learning areas from different windows and how to teach the IC using the appropriate teaching strategies.

The above view implies that Mrs Orange thought that the workshops did not fully prepare her to teach IC. This was evident from all the observed lessons that were dominated by teacher-centred approaches. She presented the lesson objectives and asked the learners about the previous lesson. From there she presented all the information and the learners were just the recipients.

Mr Red stressed the view that the CPD programmes played a vital role in changing the teachers' perceptions regarding the new curriculum:

...after attending the workshops several times, I then understood the teaching strategies needed to facilitate the IC learning.

Mr Red's story matched his teaching practice. He facilitated learning in all the lessons that I observed. $\mathrm{He}$ used brain-storming and group discussions quite often. $\mathrm{He}$ introduced the lesson by communicating the lesson objectives and then giving the learners a few minutes to think about them or asking them to form groups, assigning them topics. The learners presented what they knew. He 
sometimes let the learners argue until they reached a consensus about the correct information on the concept being taught. He provided the conclusion and the assessment. This process is illustrated in the extract below:

Mr Red: what are the Basotho music genres? [He moves in between learners' desks encouraging learners to respond].

Learner 1: Music sung by Basotho.

Learner 2: Basotho music.

Learner 3: Basotho music.

Mr Red: come on, come on others. What are they?

Learner 4: songs of Basotho.

Mr Red: ok my good learners, you are correct. Basotho music genres are all the types of music sung particularly by Basotho people in different settings.

Learner 5: in which setting sir?

Mr Red: good question but keep it for a while, we shall come to that. Let's continue. Name 4 different Basotho music genres and people who sing them in terms of boys and girls.

Learners: [in a Chorus] Mohobelo.

Mr Red: not in a chorus but raise up your hands.

Learner 1: Mohobelo and ndlamo are sung by boys

Learner 2: Mohobelo boys

Learner 3: Mokhibo and mokopu are sung by girls.

The stories from the participants indicated that the CPD programmes in the form of workshops helped them to develop their perceptions towards the teaching of the IC. These programmes had shed some light about what the IC entails and how to teach it. However, the three participating teachers, when observed in the classroom, revealed that they were still using teacher-centred and not learner-centred approaches. They were not in line with the IC teaching strategies. Only Mr Red used learner-centred approaches.

\subsubsection{Sub-theme 2: Teacher beliefs on IC assessment implementation}

According to Donaghue [27], teachers' beliefs enable them to implement the proposed changes. Therefore, there should be a correlation between CPD programmes and classroom practice in order to draw the same underlying beliefs regarding the implementation of reforms in schools. The teachers' perspectives were explored in order to understand teachers' beliefs about IC assessment techniques and how they influence their classroom practice [45].

Based on how the teachers understand the IC assessment methods, Mrs Green indicated that the CPD programmes shed some light on the IC assessment methods but she felt it was not easy applying all these forms of continuous assessment:

The workshops really shed some light about the use of IC continuous assessment in the classroom but it is not easy to apply all forms of continuous assessment due to the time constraints.
In contrast, Mrs Green assessed the learners' performance following the intended lesson plan assessment method. The story of Mrs Green on the use of assessment indicated that although she believed that CPD had not fully equipped her with regards to the IC assessment methods, the lesson that was observed revealed that she did use the continuous assessment prescribed by the CAP. Similarly, Mrs Yellow followed her intended assessment methods as she implemented the IC in class, yet she believed that assessing different competences in one lesson was not that easy:

I am trained to use both summative and formative forms of IC assessment but I feel challenged by assessing different learner competences in one lesson.

Mr Red believed that he understood the IC assessment methods because of the professional development that he had received in the workshops:

The training workshop and cluster workshops enlightened me about the IC assessment methods and now I understand them and apply them in my teaching.

Mr Red's opinion was evident in all of the lessons of his that were observed. Mr Red followed the assessment criteria indicated from his lesson plans.

Lastly, Mrs Orange's assertion was that 'I am trained to use continuous assessment in class and I definitely use it in teaching the $I C$ ' and this indicated that she was trained to use continuous assessment methods in the workshops and she assesses the learners using summative and continuous assessment in class. Mrs Orange matched what she had said about using correct assessment methods in her observed lesson. She used all the assessments, as she had indicated in her lesson plans.

The three participants indicated that the CPD programmes had changed their beliefs positively because they were equipped with knowledge and skills that enabled them to implement the IC assessment methods according to the CAP. The fourth participant indicted that she still believed that she had challenges regarding the assessment of different competences in one lesson. However, all the participants followed the intended assessment methods of their lesson plans in the classroom. This set of findings shows how the teachers' perception of assessment was shaped by the policy signals and influenced their practice.

\subsubsection{Sub-theme 3: Teacher attitudes on IC implementation}

CPD is a factor that shapes teachers' practice and helps them to adapt to the new curriculum in their school. Teachers' attitudes shape or influence how they implement the reforms because they are not passive recipients of an innovation. The exploration of teachers' perspectives was made in order to gain some insight into the attitudes that the teachers had developed towards IC implementation 
owing to their participation in CPD.

The participant teachers demonstrated different attitudes towards the implementation of IC. Mrs Green mentioned that the CPD programmes changed her attitudes towards IC:

...the workshops helped me a lot because they gave some clarity on how it was going to be implemented.

Correspondingly, Mr Red had the same view that he benefitted from the cluster workshops and he implemented the IC according to CAP recommendations:

The knowledge and skills that I acquired from the cluster workshops automatically helped me to change my approach in implementing the IC.

Mrs Yellow had the same opinion that the workshops helped her to enjoy teaching the IC:

I have been trained to teach IC. I am now competent enough to teach it.

Mrs Orange had a different view from the other three participants. She indicated that she still struggled to teach the IC:

Even after attending the cluster workshops I find myself still struggling to implement the IC according to the CAP because of the limited resources in my school and because I have acquired limited skills....

Three of the participants seemed to be happy about the workshops that they had attended regarding the implementation of the IC. They indicated that they benefited from the workshops and their teaching of the IC had changed. However, the other participant indicated that the CPD programmes had failed to change her teaching practice because she still struggled with the implementation of the IC according to CAP. This set of the findings implies that because teachers attended different cluster workshops that might be differently organised, they benefitted differently from them and therefore their attitudes varied significantly towards the IC implementation. That is, three of the participants seemed to have positive attitudes towards teaching the IC while one participant had a negative attitude. One may conclude that there is a contradiction between the findings from the observation and the findings from the interviews. All the lessons observed showed that all the participants had developed positive attitudes towards the implementation of the IC in terms of planning and teaching. The participating teachers designed their lesson plans using the syllabus and followed them in teaching from instruction to assessment, as indicated in the first and the second themes

\subsubsection{Sub-theme 4: Teachers' perceptions on IC learner outcomes}

The improved teaching practices are the result of a well-structured CPD. The teachers' perceptions of learner outcomes were explored with regard to the implementation of learner-centred teaching as a result of participation in CPD activities. Learner-centred approaches are strategies that include active learning that is thought to promote learner outcomes. Mr Red indicated that he was happy to have participated in CPD and he is competent in teaching IC as prescribed:

I engage the learners and let them find information. Therefore, I obtain good results. The learners seem to understand because they take control of their learning.

Mr Red's view was evident in his observed lessons; these indicated active learning through the learners' participation. The learners were able to ask and answer the questions in class. They shared knowledge in groups as well as through other leaner-centred techniques (cf. sub-theme 2, Mr Red's extract).

Mrs Green indicated that the level of the learners' participation differed depending on the different learning outcomes being targeted. Some learning outcomes were complex while others were simple:

The variation of learning areas motivates the learners as they cater for every learner's ability and encourage learner participation except for the concepts that are complex and high for the level of the learners.

Mrs Green's view indicated that the learners did not actively participate when they were learning complex concepts and that they needed the use of both teacher-centred and learner- centred teaching. For example in the extract below:

Teacher's action: ask the learners to explain the meaning of love and kindness (she repeats the question several time moving around in the classroom)

Learners' actions: (they were passive and silent)

Teacher's action: Repeats the question switching codes to Sesotho ("lerato le mohau keng?")

Learners' actions: (puzzled) still not responding

To resolve the above situation the teacher decided to use teacher-centred explanations as shown below.

Teacher's action: Love and kindness is shown by "caring, sharing, friendship, helping and playing" so when you share your lunch box with others you show love and kindness. When you realise that your friend does not have shoes and you have two pairs of shoes and you decide to give one pair to him/her, then you are showing love and kindness. If you lend others your belongings such as pencils and rubbers, that is love and kindness. Even when playing with others peacefully then you are showing love and kindness. Now give me examples of things that you can do to show love and kindness... 
Table 4. Mrs Yellow' lesson plan objectives segment

Objective 1: At the end of the lesson, the learners will be able to sort small animals according to colour, size and similarity in body parts.

Objective 2: At the end of the lesson, the learners should begin to sort small animals according to colour, size and similarity in body parts.

The lesson was dominated by teacher-centred teaching methods and an outcome of learner participation was hardly achieved. Mrs Green's extract implies that learner outcomes varied based on the different concepts being taught. Similarly, Mrs Yellow indicated that it was not always possible for her learners to participate actively all the time:

When teaching some concepts, the learners are able to gather the relevant information to facilitate learning while they fail to do so with other concepts.

Table 4 shows an example of one lesson objective segment. During that lesson presentation, I observed that the learners were not able to sort the collection of small animals according to the body parts and it resulted in teacher-centred teaching where the learners acted as empty vessels and recipients of knowledge

The preceding discussion indicates that Mrs Yellow found it difficult to use learner-centred strategies to teach complex concepts that ensured holistic learning as prescribed in CAP. There is a need for further training organised by the MoET and NCDC to clarify some of the concepts so that teachers can fully understand the IC and as a result learners' outcomes may improve. Mrs Orange highlighted how differently she experienced workshops organised by MoET and cluster workshops. She said that the MoET training workshops had failed to train her to teach the IC but she felt the cluster workshops had done their job:

It is only the cluster workshops that helped me to teach the IC that led to improved learner outcomes because we help one another with both theory and practice. I can therefore afford to follow the IC teaching methods. The learners also follow the lesson and actively participate. They obtain good results at the end of each level.

The participants' stories reveal a variety of views regarding how the CPD programmes influence the learners' outcomes. Two participants highlighted that in the training workshops the facilitators discussed how to teach the IC whilst the cluster workshops had assisted by actually showing them how to teach the IC. One participant elaborated that the training workshop had failed to teach her how to teach the IC hence she had relied on the cluster workshops, which according to her, were not sufficient to help her improve the learners' outcomes. Mr Red, however, had different experiences. He indicated that both the training and cluster workshops helped him to implement the IC according to the CAP and he had obtained good results. This set of findings implies that although all the participants attended the IC training workshops and different cluster workshops, they had different views on how these programmes changed their perceptions towards the implementation of the IC according to the CAP prescriptions. The findings indicate that the teachers found simple concepts easy to teach but they struggled to teach more complex concepts. It is therefore necessary for teachers to be provided with CPD monitoring programmes that evaluate the effectiveness of such programmes and for MoET to pay school visits to monitor how teachers implement the IC in schools.

\section{Discussion}

This is a qualitative multiple case study using semi-structured interviews and lesson observations that explored CPD activities for the implementation of the IC, which intends to shape the teachers' perspectives on the curriculum project in Lesotho. Four perspectives were identified as the main findings of the study and contributed to the insights and knowledge of the role of CPD programmes in shaping teachers' perceptions regarding the implementation of IC reforms in schools.

The first finding is that although the four participants indicated that the CPD programmes assisted them with the knowledge to implement IC, the classroom observations revealed that three participants were still using teacher-centred approaches apart from Mr Red who used learner-centred approaches. This finding seems to align with the SMT's postulation that teachers' understanding of the "policy intentions is an individual, social as well as contextual matter" [32: 349], this as evidenced in the gaps between teacher interpretations and the intentions of the policy. This finding seems to show that although the CPD programmes may influence what the teachers claim about what they ought to know about the curriculum implementation, they display gaps in the practical implementation of the IC. The inefficiencies are manifested in their over-reliance on teacher-centred approaches. However, one teacher's claim of having the knowledge to implement IC effectively matches what he did in the classroom. He claimed to have understood that the new curriculum required that he use the learner-centred approach and he managed to implement this in his classroom. The implication from this finding seems to point to the importance of the content component of the PD framework by Desimone [2]. It seems that using learner-centred approaches should be part of the content that needed to be emphasised. Harrell [46] and Fuand 
Sibert [47], report that many teachers are not competent to teach the IC. This finding is supported by [47] who conclude that "teachers' inadequate content knowledge in different subject areas prevents them from identifying the key ideas to be covered in teaching of the IC." Therefore the shaping of how teachers perceive their knowledge to implement the IC varies and shows that the CPD programme does not adequately enough change the teachers' perceptions on the implementation of the IC. Although Mensah [48] posits that teachers benefit from the CPD programmes that they attend, there are also other areas of professional development where they do not benefit. The content of the CPD programmes should include, among other things, the content to be taught in classrooms and the recommended teaching strategies.

The second finding revealed that three participants indicated that the CPD programmes had positively changed their beliefs because they were equipped with knowledge and skills that enabled them to implement the IC assessment methods according to the CAP. The fourth participant indicated that she still believed that she had some challenges with regard to the assessment of different competences in one lesson. All the participants followed the intended assessment methods of their lesson plans in the classroom. However, it seems that the use of different types of assessments in one lesson is one of the content areas that must be emphasised during the CPD activities. These sets of findings imply that individual teachers have different beliefs regarding the IC assessment methods that influence their teaching practice. The findings also indicate that individual teachers make sense by constructing reality through the creation of meaning coming from their prior knowledge, experience and beliefs [49]. The opinion of the participating teachers is that CPD benefitted them in terms of outlining how assessment should be conducted. The only challenge was for them to implement all the four types of assessment in one lesson. They realised there were benefits for the transformation of their teaching practice with regard to the use of the prescribed assessment methods. Prescription of strategies as opposed to cases where there are no clear prescriptions seemed to be very influential for the teachers' beliefs and perceptions. It also seemed it would be easier to emphasize prescribed assessments in the CPD activities. Consequently, as [50] suggests the beliefs guided the teachers' teaching practice which in this case was assessment in the context of IC. Once beliefs and perceptions have been allowed to form, they influence teachers' classroom behaviour, decision-making and interactions with the learners. Every individual teacher is unique. "Teachers' beliefs, values, practices and interests are normally not taken into account by policymakers and this hinders implementation of reforms because teachers may not understand the foundations for curriculum change" [51]. Teachers' beliefs have to be taken into consideration whenever CPD programmes are organised. Le Cornu [35] indicates that teachers' beliefs have an impact on their resilience in solving the problems that they encounter in teaching, especially when using the forms of assessment methods designed to measure the attainment of learning outcomes. It is generally asserted that CPD activities develop teachers' knowledge, teaching skills, attitudes and beliefs that help them to enhance their classroom practice [52]. CPD activities should be planned in such a manner that they support and assist teachers to change their teaching practice and they should recognise that teachers' beliefs and experiences related to the roles that they need to fulfill [53], because of what teachers do to identify how their perspectives are being shaped by CPD activities[54]. The perspectives strongly predict their decisions that ultimately influence their classroom practices and learning outcomes. For instance, teachers' beliefs enable them to make decisions about their classroom teaching and learning as indicated [25] because beliefs play a key role in teachers' classroom practice and their professional development. Teachers' perspectives should be shaped carefully and successfully. If not, teachers may continue with their former practice in the belief that it is a new practice [55]. Similarly, if teachers do not feel competent to teach and are unfamiliar with the curriculum, then these beliefs may influence how they respond and how they teach the curriculum [56].

The third finding is that three participants seemed to have a positive attitude towards the teaching of the IC while one expressed misgivings about it, possibly due to their CPD experiences. Besides the misgivings expressed by one of the teachers during the interviews, all the observed lessons showed that the participants have developed positive attitudes towards the implementation of IC in terms of planning and teaching. They designed their lesson plans based on the syllabus and followed them in teaching the prescribed content from the instruction stage to assessment. However, as indicated earlier, there was an over reliance on teacher-centred strategies. This finding implies that CPD programmes influenced the sense-making that teachers made in relation to the reforms [32]. According to Desimone [2] CPD should be comprehensive and holistic (coherent) by addressing the teachers' content needs, through active learning, collaboration and also that these learning experiences should be conducted continuously. The fact that not all the teachers felt the same about the teaching of IC suggests that the CPD activities influenced their perspectives differently possibly due to the contextual settings in which the central training and cluster workshops were conducted. As a result, the quantity and quality of the support that they received during the reform implementation influenced the quality of the policy implementation [32]. Costley [57] argues that some teachers in South African schools do not implement the policies recommended by the IC but opt to teach subjects separately. According to [29], the assumption that CPD programmes lead to changes in classroom practice and in turn lead to a change of teachers' attitudes and beliefs, ultimately leading to a change in learner outcomes, 
may open more questions and encourage further research as these changes seem to differ from one teacher to another. The participating teachers had positive intentions to implement the IC based on their sense-making, but sometimes they were inadequately prepared for its implementation [58].

The fourth finding of this study revealed that the participating teachers had different views regarding how CPD programmes help them to teach the IC according to the CAP prescriptions and thereby to improve the learning outcomes. The evidence is that it was easier for the teachers to improve the learners' outcomes when they taught less complex concepts but it was more difficult to realise the positive learning outcomes with more complex concepts. The study concludes that according to the participating teachers' perspectives, the CPD programmes have both a positive and a negative influence on learning outcomes. These learning outcomes are related to active learning as prescribed by the CAP for IC. The teachers used sense-making to choose one option over another when they encountered some conflicts between the expected reform objectives and their teaching practice, based on their beliefs [59]. That is, teachers may construct meaning that either reinforces their pre-existing practices or rather focuses on the changes of the proposed reform [60]. More importantly, one of the constraints was that the teachers were not trained to teach IC at university and therefore had challenges when putting it into practice [46].

The findings imply that although the study participants attended the IC training workshops and regular cluster workshops (CPD programmes) for the implementation of the IC, the manner in which their perspectives of the IC are shaped by CPD varied. The CPD programmes changed their perspectives differently due to the different senses that teachers made about the programmes. That is, teachers perceptions of teacher knowledge, beliefs, attitudes and learning outcomes in the process of the IC implementation were shaped differently - they were positive for some teachers but negative for others based on their sensemaking.

\section{Conclusions}

The findings of this study contribute to the literature on how CPD programmes shape teachers' perspectives on new curriculum projects which in this case was the implementation of the IC. The findings reveal that CPD programmes had guided teachers' beliefs, attitudes (through sense-making) in ways that influenced the learners' outcomes positively. This was the case for some teachers when their attitude or belief was aligned with the curriculum policy of the IC. In cases where the CPD activities failed to guide the teachers' perspectives in ways that aligned with the curriculum policy, the teachers struggled to implement some of the requirements of the IC.
The teachers' perspectives of the IC curriculum project that were shaped were whether to use teacher-centred or learner-centred strategies, how to use integrated assessment approaches, attitude towards the usefulness of IC and the influence of CPD activities on learning outcomes. These findings show areas that might be targeted for further teacher development by carefully planning for the content to be covered and taught during the CPD activities. The perspectives on the areas indicated above may also serve as indicators to determine how to respond to teacher learning needs according to Desimone [2] in terms of content learning, how teachers learn (actively or collaboratively), the frequency of learning sessions and development of coherent learning programmes.

\section{Recommendations}

The study recommends that the government should provide primary school teachers with effective CPD programmes that consider the teachers' curriculum sense-making, beliefs that guide the implementation and attitudes towards the IC. There should be follow-up programmes that monitor and evaluate the influence of CPD programmes in all the schools involved with the IC implementation. This may enable the policy-makers to identify the gap between the policy and practice and make some modifications where necessary.

\section{Acknowledgements}

I would like to express my sincere gratefulness to the Lord, God Almighty, my supervisor Dr Maria Tsakeni, the schools and the teachers who participated in this research project and provided responses for the study, the financial support and guidance provided by the office of the SANRAL Chair in Mathematics, Natural Sciences and Technology Education as well as the following editors for their great contributions in this study; Ms Beverley Wilcock; editor in the SANRAL chair's office, Professor Moloi; Associate Professor, English Department, Faculty of Humanities, National University of Lesotho and Derek Griper, lecturer at University of Cape town.

\section{Appendices}

\section{Appendix: 1 Interview protocol}

Teachers' perspectives on professional development for classroom implementation of the integrated curriculum in Lesotho

This research study aimed to investigate how the CPD activities for the implementation of the IC shape the 
teachers' perspectives on the curriculum project in Lesotho.

\begin{tabular}{|l|l|l|l|l|}
\hline \multirow{2}{*}{ Key issues } & \multicolumn{3}{|c|}{ Participants } \\
\cline { 2 - 5 } & A & B & C & D \\
\hline Teachers' biography & & & & \\
\hline $\begin{array}{l}\text { Teachers' perspectives on professional } \\
\text { experiences for the implementation of the IC. }\end{array}$ & & & & \\
\hline $\begin{array}{l}\text { Teachers' perspectives on the influence of the } \\
\text { CPD activities on classroom practice. }\end{array}$ & & & & \\
\hline $\begin{array}{l}\text { Teachers' perspectives on how CPD activities } \\
\text { shape their beliefs and attitude on IC. }\end{array}$ & & & & \\
\hline
\end{tabular}

\section{REFERENCES}

[1] Mokhele, M. \& Jita, L. South African teachers' perspectives on continuing professional development: a case study of the Mpumalanga Secondary Science Initiative. Procedia Social and Behavioral Sciences, 9, 1762-1766, 2010.

[2] Desimone, L. M. Improving impact studies of teachers' professional development: toward better conceptualizations and measures. Educational Researcher, 38(3), 181-199, 2009.

[3] Lee, I. Teachers as presenters at continuing professional development seminars in the English-as-a-foreign-language context: 'I find it more convincing'. Australian Journal of Teacher Education (Online), 36(2), 1-30, 2011.

[4] Ministry of Education and Training (MoET) Lesotho. Curriculum and Assessment Policy Framework. Maseru: The Age Multimedia Publishers, 2009.

[5] Raselimo, M. \& Mahao, M. The Lesotho curriculum and assessment policy: Opportunities and threats. South African Journal of Education, 35(1), 1-12, 2015.

[6] Malik, A. \& Malik, R. Twelve tips for developing an integrated curriculum. Medical Teacher, 33(2), 99-104, 2011.

[7] Brauer, D. G. \& Ferguson, K. J. "The integrated curriculum in Medical Education: AMEE Guide No. 96". Medical Teacher, 37(4), 312-322, 2015.

[8] Petersen, J. "The development of Tourism as a young school subject: A comparative curriculum Analysis", Med Dissertation, University of Cape Town, 2015.

[9] Nhlapho, M. Moreeng, B. \& Malebese, M. Challenges facing implementation of an integrated Tourism curriculum: The Experiences of teachers in Lesotho. Journal of Education and Practice, 10(5), 92-101, 2019.

[10] Tankiso-Mphunane, L. M. "Investigating the Factors that Attribute to the Teachers' Failure to Integrate Mokhibo and Ndlamo with Business in the Three Butha-Buthe High Schools", Med Dissertation, National University of Lesotho, 2014.

[11] Remijan, K. W. Improving teacher motivation in secondary schools with hybrid positions. American Secondary Education 42(3), 30-38, 2014.
[12] Ha, M., Baldwin, B. C. \& Nehm, R. H. The long-term impacts of short-term professional development: Science teachers and evolution. Evolution: Education and Outreach, 8(1), 1-11, 2015.

[13] Kempton, J. To Teach, to Learn: More Effective CPD for Teachers. London: Centre Forum, 2013.

[14] Fullan, M. The new meaning of educational change (5thed.). New York and London: Teachers College Press, 2016.

[15] Rose, J. \& Reynolds, D. Teachers' continuing professional development: A new approach. Paper presented at $20^{\text {th }}$ Annual World International Congress for School Effectiveness and Improvement, Nigeria, 2017.

[16] Opfer, V. Darleen \& Pedder, D. 'Benefits, status and effectiveness of Continuous Professional Development for teachers in England'. Curriculum Journal, 21(4), 413-431, 2010.

[17] Towers, J. Administrative supports and curricular challenges: New teachers enacting and sustaining inquiry in schools. Canadian Journal of Education, 35(1), 259-278, 2012.

[18] Ucana, S. The role of continuous professional development of teachers in educational change: A literature review. Harran Education Journal, 1(1), 36-43, 2016.

[19] Selepe, C. Curriculum reform in Lesotho: Teachers' conceptions and challenges. (Unpublished $\mathrm{PhD}$ thesis). Johannesburg: University of the Witwatersrand, 2016.

[20] Makara, M. C. Improving teachers' pedagogical practices through lesson study in secondary schools in Maseru Lesotho. (Unpublished doctoral dissertation). Central University of Technology, Free State, 2016.

[21] Khechane, N. C. Developing a model for assessment in primary schools in Maseru, Lesotho. PhD thesis, Central University of Technology, Free State. Bloemfontein, 2016.

[22] Shelile, L. I. \& Hlalele, D. Challenges of continuing Professional teacher development in inclusive Lesotho Schools. International Journal of Educational Sciences, 7(3), 673-686, 2014.

[23] Aihi, B. Teacher concerns about the outcomes-based reform curriculum in Papua New Guinea. Contemporary Papua New Guinea studies, 14, 13, 2011.

[24] Atta, G. Exploring teachers' perspectives on the availability of professional development programs: A Case of one district in Ghana. International Journal of Humanities and Social Science, 7(1), 1-12, 2015.

[25] Kuzborska, I. Links between teachers' beliefs and practices and research on reading. Reading in a foreign language, 23(1), 102-128, 2011.

[26] Park, M. and Sung, Y. K. Teachers' perceptions of the recent curriculum reforms and their implementation: What can we learn from the case of Korean elementary teachers? Asia Pacific Journal of Education, 33(1), 15-33, 2013.

[27] Donaghue, H. An instrument to elicit teachers 'beliefs and assumptions. English Language Teaching Journal, 57(4), 344-351, 2003.

[28] Fullan, M. The new meaning of educational change (4thed.). London: Routledge, 2008. 
[29] Guskey, T. R. Professional development and teacher change. Teachers and Teaching, 8(3), 381-391, 2010.

[30] OECD. Creating Effective Teaching and Learning Environments: First Results from TALIS. Paris: Organization for Economic Co-Operation and Development. http://www.oecd.org/document/54/0,3343,en_2649_39263 231_42980662_1_1_1_1,00.html,2009.

[Accessed:23May2018].

[31] Pedder, D. Organisational conditions that foster successful classroom promotion of learning how to learn. Research Papers in Education, 2(12), 171-200, 2006.

[32] Spillane, J., Reiser, B. \& Reimer, T. Policy implementation and cognition: Reframing and refocusing implementation research. Review of Educational Research, 72(3), 387-431, 2002.

[33] Schechter, C, Shaked, H., Ganon-Shilon, S. \& Goldratt, M. Leadership metaphors: School principals' sense-making of a national reform. Leadership and Policy in Schools, 04.01.2017tarihindehttp://www.tandfonline.com/loi/nlps20 adresindenerişilmiştir, 2016. [Accessed: 20 January 2019].

[34] Coburn, C. Shaping teacher sense-making: School leaders and the enactment of reading policy. Educational Policy, 19(3), 476-509, 2005.

[35] Le Cornu, R. Building early career teacher resilience: The role of relationships. Australian Journal of Teacher Education, 38(4), 1-16, 2013.

[36] Creswell, J. Research design: Qualitative, Quantitative, and Mixed Methods Approaches. California. USA: Sage Publication, 2014.

[37] Denzin, N. K. \& Lincoln, Y. S. The SAGE Handbook of Qualitative Research. Thousand Oaks: Sage Publications, 2011.

[38] McCracken, N. A. Principal Perceptions of Professional Development (Doctoral dissertation, University of Pittsburgh), 2017.

[39] Saldana, J. The coding manual for Qualitative researchers. Thousand Oaks, CA: Sage Publications, 2016.

[40] Creswell, W. J. Research Design: Qualitative, Quantitative, and Mixed Methods Approaches (Edition illustrated). California: SAGE Publications, 2013.

[41] Creswell, J. W., Ebersohn, L., Eloff, I., Ferreira, R., Ivankova, N. V., Jansen, J. D., Nieuwenhuis, J., Pieterson, J., Pano Clark, V. L. \& Vander Westhuizen. First steps in Research. Pretoria: Van Schaik Publishers, 2010.

[42] Maree, K. (Ed.). First steps in research. Pretoria: Van Schaik, 2016.

[43] Johnson, B. \& Christensen, L. Educational research: Quantitative, Qualitative and Mixed Approaches. London: Sage Publications, 2008.

[44] Ganon-Shilon, S. \& Schechter, C. School principals' sense-making of their leadership role during reform implementation. International Journal of Leadership in Education, 22(3), 279-300, 2019.

[45] Farrell, T. S. and Mom, V. Exploring teacher questions through reflective practice. Reflective Practice, 16(6), 849-865, 2015.

[46] Harrell, P. E. Teaching an integrated science curriculum: Linking teacher knowledge and teaching assignments. Issues in Teacher Education, 19(1), 145-165, 2010.

[47] Fu, Y. \& Sibert, S. Teachers' Perspectives: Factors That Impact Implementation of Integrated Curriculum in K-3 Classrooms. International Journal of Instruction, 10(1), 169-186, 2017.

[48] Mensah, D. K. D. Teacher professional development: Keys to basic school teachers' curriculum practice success in Ghana. International Journal of Interdisciplinary Research Method, 3(2), 33-41, 2016.

[49] Spillane, J. \& Anderson, L. The architecture of anticipation and novices' emerging understandings of the principal position: Occupational sense-making at the intersection of individual, organization and institution. Teachers College Record, 116(7), 1-42, 2014.

[50] Gilakjani, A. P. \& Sabouri, N. B. Teachers' beliefs in English language teaching and learning: A review of the literature. English Language Teaching, 10(4), 78-86, 2017.

[51] Glatthom, A. A. The principal as curriculum leader: Shaping what is taught and tested. Philadelphia: Corwin Press, 2000.

[52] Van Kuijk, M. F., Deunk, M. I., Bosker, R. J. \& Ritzema, E. S. Goals, data use, and instruction: The effect of a teacher professional development program on reading achievement. School Effectiveness and School Improvement, 27(2), 135-156, 2016.

[53] Nabhani, M. \& Bahous, R. Lebanese teachers' views on continuing professional development. Teacher Development, 14(2), 207-224, 2010.

[54] Amiryousefi, M. Iranian EFL teachers and learners' beliefs about vocabulary learning and teaching. International Journal of Research Studies in Language Learning, 4(4), 29-40, 2015.

[55] Timperley, H., Wilson, A., Barrar, H. \& Fung, I. Teacher professional learning and development: Best evidence synthesis iteration (BES). Wellington, New Zealand: Ministry of Education, 2007.

[56] Bautista, A., Ng, S., Múñez, D. \& Bull, R. Learning areas for holistic education: Kinder garden teachers' curriculum priorities, professional development needs, and beliefs. International Journal of Child Care and Education Policy, 10(1), 1-18, 2016.

[57] Costley, K. C. Research supporting integrated curriculum: Evidence for using this method of instruction in public school classrooms, 2015. https://eric.ed.gov/?id=ED55291 6. [Accessed:10 April 2018].

[58] Dowden, T. Challenging, integrated, negotiated and exploratory curriculum in the middle years of schooling: Designing and implementing high quality curriculum integration. Australian Journal of Middle Schooling, 14(1), 16-27, 2014.

[59] Gawlik, M. Shared sense-making: How charter school leaders as crib meaning to accountability. Journal of educational administration, 53(3), 393-415, 2015. 
[60] Coburn, C. E., Hill, H. C. \& Spillane, J. P. Alignment and accountability in policy design and Implementation: The common core state standards and Implementation research. Educational Researcher, 45(4), 243-251, 2016. 